\title{
Satisfação no trabalho e clima organizacional: A relação com autoavaliações de desempenho
}

\author{
Job satisfaction and organizational climate: Relation with \\ self-assessments of performance \\ Satisfacción en el trabajo y clima organizacional: Su relación con \\ autoevaluaciones de desempeño
}

\author{
Alexandre Pinto Vieira de PAULA ${ }^{1}$ \\ Fabiana QUEIROGA \\ Centro Universitário de Brasília, Brasília, DF, Brasil
}

Resumo

Uma das grandes preocupações dos gestores é manter bons níveis de desempenho no trabalho, de forma a garantir bons diferenciais para as organizações. As características contextuais e individuais aparecem como variáveis importantes que auxiliam as organizações a manter esses diferenciais e, com isso, patamares elevados de competitividade. Esta pesquisa se propõe a analisar a relação entre duas variáveis, identificando pontos comuns entre os construtos e a relação com o desempenho medido por meio de autoavaliações. Para a coleta dos dados foram utilizadas três escalas: a Escala de Autoavaliação de Desempenho no Trabalho (EGDT), a Escala de Clima Organizacional (ECO) e a Escala de Satisfação no Trabalho (EST). Participaram da pesquisa 152 funcionários de duas organizações, sendo a maioria homens (57\%), com média de idade de 35 anos e com predominância do nível de escolaridade ensino médio completo (28\%). As análises de correlação apontaram que os fatores comuns observados nas medidas de satisfação e clima organizacional não apresentam multicolinearidade (maior magnitude observada foi de $r=0,78 ; p<0,01$ ). Além disso, nas análises de regressão, os fatores Recompensa, Natureza do trabalho e Controle/pressão contribuíram individualmente para a explicação das duas autoavaliações $(p<0,05)$. Em pesquisas futuras, sugere-se aprofundar o diagnóstico do contexto organizacional por meio de entrevistas e observações, e complementar as avaliações com indicadores organizacionais de desempenho. Palavras-chave:

Desempenho individual; satisfação no trabalho; clima organizacional.

\section{Abstract}

One of managers' major concerns is related to maintaining good performance levels at work, to ensure differential advantage to their organizations. Contextual and individual characteristics are perceived as important variables that help organizations maintain their distinctiveness and, consequently, high levels of competitiveness. The current research aims to analyze the relationship between these two variables, identifying commonalities between the constructs and the relationship with performance measured through self-assessments. Three scales were used for data collection: the Self-Assessment of Performance at Work Scale, the Organizational Climate Scale, and the Job Satisfaction Scale. Taking part in this research were 152 employees from two organizations, mostly men (57\%), with an average age of 35 years, and predominantly with a high school degree (28\%). Correlation analysis showed that common factors observed in measures of satisfaction and organizational climate show no multicollinearity (largest observed magnitude was $r=0,78 ; p<0,01$ ). Additionally, regression analyses suggested that the dimensions Reward, Nature of the Work, and Control/Pressure individually explained the participants' two self-assessments $(p<0,05)$. Future research could more fully explore the diagnosis of the organizational context through interviews and observations, and additional evaluations of organizational performance indicators.

Keywords:

Individual performance; job satisfaction; organizational climate. 
Una de las grandes preocupaciones de los gestores es mantener buenos niveles de desempeño en el trabajo para garantizar buenos diferenciales en las organizaciones. Las características contextuales e individuales aparecen como variables importantes que auxilian a las organizaciones a mantener estos diferenciales y, con eso, niveles elevados de competitividad. La presente investigación se propone analizar la relación entre dos variables, identificando puntos en común entre los constructos y la relación con el desempeño evaluado a través de autoevaluaciones. Para colectar los datos fueron utilizadas tres escalas: Escala Autoevaluación de Desempeño en el Trabajo, Escala de Clima Organizacional y la Escala de Satisfacción en el Trabajo. Participaron de la investigación 152 funcionarios de dos organizaciones, donde la mayoría era hombres (57\%) con con una edad promedio de 35 años y con un nivel educativo de secundaria completa (28\%). Los analices de correlación sugieren que los factores comunes observados en las medidas de satisfacción y clima organizacional no presentan multicoliniariedad (mayor magnitud observada fue de $r=0,78 ; p<0,01$. Además, en los analices de regresión los factores Recompensa, Naturaleza del Trabajo y Control/Presión contribuyen individualmente para la explicación de las dos autoevaluaciones $(p<0,05)$. En investigaciones futuras, se sugiere profundizar el diagnóstico del contexto organizacional por medio de entrevistas y observaciones complementares a las evaluaciones con indicadores organizacionales de desempeño.

Palabras-clave:

Desempeño individual; satisfacción en el trabajo; clima organizacional.

\section{$\mathrm{N}$}

a sociedade competitiva de hoje, as organizações buscam diferenciais para se destacarem no mercado e conseguirem vender seus produtos ou serviços. Uma organização que não consegue atingir bons índices de desempenho dos funcionários perde em competitividade para os concorrentes. Por isso, uma das grandes preocupações dos gestores é manter bons níveis de desempenho no trabalho, que garantam a rentabilidade da empresa em patamares elevados e proporcionem diferenciação de ofertas (Porter, 1996).

As organizações são cada vez mais complexas, ocupando novos espaços, que demandam a integração entre necessidades da empresa e competências individuais e coletivas (Dutra, 2004). Nesse cenário, as variáveis que fazem parte dos bens intangíveis da organização, envolvidas na gestão de pessoas, são valorizadas, para além do foco nas máquinas e materiais (Antão, 2009). Nesse sentido, cabe relembrar o estudo de Elton Mayo na fábrica da Wester Eletric, localizada em Hawthore, Estados Unidos, ocorrido na década de 1920 (Pedro, 2006). No caso em questão, um grupo delimitado de funcionários teve melhorias nas condições de iluminação, resultando em aumento de sua produtividade. Depois, adicionaram-se intervalos para descanso e foram oferecidos lanches; a produtividade continuou aumentando. Finalmente, retiraram-se todos os benefícios e, surpreendentemente, a produtividade aumentou ainda mais (Pedro, 2006). O estudo mostra que a qualidade das relações entre os gestores e os trabalhadores impacta no desempenho. No caso, os funcionários eram tratados de forma diferente, pois faziam parte de um grupo especial, submetido a condições novas. O fato de se sentirem diferentes os motivou a produzir mais, independentemente das condições materiais oferecidas. Elton Mayo, assim, destacou que o método de trabalho não é o único responsável pelo desempenho, pois há outras variáveis envolvidas (Maximiano, 2007).

Muitas décadas de estudo se passaram e hoje as variáveis que impactam o desempenho estão mais claras. Estudam-se variáveis contextuais, como a formação das equipes de trabalho, as relações de poder, as condições de saúde, as características da cultura, os valores organizacionais e o clima organizacional, e variáveis individuais, como significado e envolvimento no trabalho, comprometimento organizacional, motivação para trabalhar e satisfação com o trabalho. No caso desta pesquisa, as variáveis de interesse são o clima organizacional, a satisfação e suas relações com o desempenho.

Pode-se dizer que o desempenho é o conjunto de comportamentos da pessoa no trabalho que leva a empresa a obter resultados. Além disso, pode-se dividir o desempenho no trabalho em voltado para o contexto, referente à proatividade do funcionário, o que inclui espontaneidade, altruísmo, iniciativa, responsabilidade, entre outros comportamentos não vinculados diretamente à atividade laboral; e voltado para a tarefa, que inclui os comportamentos necessários à execução direta do trabalho (Sonnentag \& Frese, 2002).

O desempenho de tarefa refere-se às contribuições técnicas do indivíduo para o núcleo do cargo ou ocupação exercida. Está relacionado aos comportamentos esperados e prescritos para a função, ou seja, intrapapel. Depende principalmente de habilidades cognitivas. O desempenho contextual, por sua vez, implica em comportamentos espontâneos e emergentes, extrapapel. Não se relaciona diretamente com as tarefas prescritas e 
técnicas de um cargo, e sim com comportamentos referentes ao ambiente psicossocial como um todo, como altruísmo, consciência, civismo e cortesia. Dessa forma, depende especialmente de habilidades emocionais e volitivas (Bendassolli \& Malvezzi, 2013).

Para analisar o desempenho, pode ser usada a avaliação do supervisor, da própria pessoa, dos pares, de uma comissão avaliadora ou avaliação $360^{\circ}$, entre outros métodos (Peixoto \& Caetano, 2013). Seja qual for o método de avaliação, é importante ressaltar que o desempenho no trabalho é diferente do resultado, que seria o produto do desempenho, suas consequências, como lucro, produtos ou serviços oferecidos. Os resultados são afetados por fatores externos ao indivíduo, como conjuntura econômica, política e dependência de outras unidades de trabalho. Nesse sentido, tais indicadores são importantes parâmetros para identificar o que deve ser considerado desempenho, mas incluí-los como único objeto de desempenho pode estruturar uma avaliação injusta e pouco ilustrativa do comportamento do indivíduo na organização. Assim, é relevante ter em conta que o sistema de avaliação deve ter como objeto as ações realizadas no cotidiano de trabalho, os comportamentos individuais (Peixoto \& Caetano, 2013).

Apesar da importância do desempenho no trabalho, poucos estudos empíricos são publicados no Brasil. $\mathrm{Na}$ literatura analisada, foi encontrado o estudo de Fonseca e Bastos (2003), que conduziram uma pesquisa em uma empresa financeira, buscando verificar as possíveis relações entre comprometimento organizacional e criatividade com o desempenho no trabalho. O desempenho foi considerado na perspectiva do Balanced Scorecard (BSC), que vai além da mensuração do comportamento, englobando processos, produtos e clientes, colocando-o como um marco estratégico dentro da organização (Kaplan \& Norton, 2000, citado por Fonseca \& Bastos, 2003). Assim, foi usada uma escala que mede a Gestão do Desempenho Profissional (GDP), com base no BSC, medindo cinco fatores: Estratégia e operações, Resultado econômico, Satisfação do cliente, Comportamento organizacional e Processos internos. Encontrou-se como resultados que os estímulos à criatividade e o padrão de comprometimento mais afetivo compõem um modelo explicativo do desempenho medido por meio do $\operatorname{BSC}\left(R^{2}=0,465 ; p<0,01\right)$.

O estudo de Fonseca e Bastos (2003) aponta para a importância de variáveis individuais e contextuais para a compreensão e explicação do desempenho no trabalho. Da mesma forma, esta pesquisa visa relacionar desempenho com clima organizacional, variável contextual, e satisfação no trabalho, variável individual. Para delimitar melhor as variáveis de interesse da presente pesquisa, suas definições serão apresentadas na sequência.

Conforme observado, o desempenho no trabalho é afetado por variáveis contextuais, como o clima organizacional. Pode-se afirmar que o clima varia, pois depende de como o contexto de trabalho afeta os comportamentos e as atitudes de quem faz parte dele (Martins, 2008; Silva, 2015). As pesquisas de clima consideram, portanto, as percepções das pessoas sobre o ambiente de trabalho que possam esclarecer melhor as várias relações, hierarquias e o próprio ambiente que perpassa a organização. Essa percepção tem impacto sobre como e quanto os funcionários trabalham (Glisson, 2007; Sousa \& Garcia, 2011).

Ao medir o clima organizacional, é importante considerar o alerta de Puente-Palacios e Martins (2013) de que clima refere-se a um atributo da organização, pois é comum na literatura localizar o clima como um atributo meso, ou seja, no nível das equipes, setores ou unidades de trabalho. Por outro lado, apesar de ser coletiva, a mensuração, em geral, ocorre no nível individual, uma vez que a organização não fornece esses dados diretamente, mas por meio dos indivíduos. Assim, é prática comum aplicar escalas psicométricas, respondidas individualmente, e calcular fatores gerais que representam o clima de um setor ou organização. Pode-se também recolher e analisar as percepções individuais compartilhadas sobre políticas, práticas e procedimentos da instituição. Ambos os caminhos são viáveis, porém, conforme ressaltam as autoras, o pesquisador deve estar ciente do nível de análise e ter definições claras.

No Brasil, há várias pesquisas recentes sobre clima organizacional que têm usado a ECO - Escala de Clima Organizacional (Martins, Oliveira, Silva, Pereira, \& Sousa, 2004), que será usada aqui para medir essa variável. Sousa e Garcia (2011) realizaram uma pesquisa em que clima foi entendido como "as influências do ambiente de trabalho sobre o comportamento das pessoas na organização" (p. 24). Os autores mediram o construto em uma rede de farmácias de Minas Gerais e encontraram um bom clima entre os funcionários, exceto no fator Controle/pressão, com escore considerado ruim. Barbosa (2011) conduziu uma pesquisa em empresas juniores do Distrito Federal, buscando correlacionar o clima organizacional com o estilo gerencial. Utilizou a ECO e encontrou melhores resultados no clima organizacional nas dimensões Apoio da chefia e da organização e Coesão entre os colegas. Pode-se citar, também, a pesquisa de Magno e Bezerra (2012), 
que utilizou a ECO para medir o clima organizacional entre promotores de vendas do agreste e sertão de Pernambuco. Encontraram que, de maneira geral, os participantes não percebem nem um clima bom, nem um clima ruim. $\mathrm{O}$ fator com pior percepção de clima foi a Coesão entre colegas.

Não são apenas as variáveis contextuais que se relacionam com o desempenho, as variáveis individuais também impactam a performance dos trabalhadores. A satisfação é uma das variáveis fundamentais para qualquer organização preocupada em manter boas práticas de gestão de pessoas. Conforme Siqueira (2008), a satisfação no trabalho refere-se ao quanto o indivíduo vivencia experiências prazerosas no contexto das organizações. Além disso, a autora enfatiza que esse conceito é multidimensional, dividido em cinco aspectos: colegas, salário, promoções, trabalho e chefia.

Cabe destacar alguns estudos recentes no Brasil sobre satisfação com o uso da EST - Escala de Satisfação no Trabalho, que será usada aqui para medir essa variável. Schröder (2012) conduziu uma pesquisa com servidores públicos de um município do Rio Grande do Sul, utilizou a EST e obteve como resultado maiores índices de Satisfação com os colegas. Também verificou bons índices de Satisfação com a chefia e com a Natureza do trabalho. $\mathrm{O}$ autor sugeriu novas pesquisas com os servidores, incluindo uma que medisse o clima organizacional. Em outra pesquisa, que relaciona Qualidade de Vida no Trabalho (QVT) com satisfação, Melo (2011) utilizou uma amostra de 159 funcionários de uma rede de supermercados e obteve bons índices de Satisfação com os colegas e com a chefia, e indiferença com o Salário, a Natureza do trabalho e as Promoções. O autor ressalta a importância de melhorar os modelos de gestão, pois eles "são determinantes para a satisfação no trabalho e a QVT dos trabalhadores e, consequentemente, para um melhor desempenho no seu trabalho" (p. 39).

O estudo de Garrido (2009), também utilizando a EST, mediu a satisfação de 91 servidores do Superior Tribunal de Justiça. Encontrou-se maior grau de Satisfação com a chefia e menor grau com as Promoções. Considerando os resultados, foram propostas políticas de promoção mais claras e com maior frequência. Nesse estudo, também destacou-se o cuidado que as organizações devem ter quanto às práticas de gestão de pessoas, visto que elas impactam na satisfação que, por sua vez, afeta o desempenho. Esses foram resultados semelhantes aos encontrados fora do contexto brasileiro em que o bem-estar psicológico e a satisfação foram considerados preditores do desempenho (Wrigth \& Cropanzano, 2000).

Ao se observar as definições dos construtos clima organizacional e satisfação no trabalho, bem como os instrumentos disponibilizados para a sua avaliação, é possível destacar várias interfaces. Apesar de se tratar de níveis conceituais distintos, ambos incluem a análise de características ambientes em comum, como a convivência com os colegas, a relação com a chefia e, ainda, a remuneração recebida. Conceitualmente, além da distinção de níveis (um pertence ao nível meso e outro ao nível individual), o clima organizacional marca-se por apresentar uma natureza cognitiva, ao passo que a satisfação envolve uma natureza afetiva (Tamayo \& Borges, 2001). Mas, será que na prática, ao se mensurar esses construtos e incorporá-los em um mesmo modelo explicativo, essa diferenciação é evidenciada?

Dessa forma, considerando a relevância das variáveis de interesse na literatura, esta pesquisa visa melhorar a compreensão dos níveis de interação entre elas, a partir de um estudo de caso em duas organizações diferentes, proporcionando dados de contextos de trabalho diversificados, com perfis profissionais variados. Uma pesquisa que correlacione essas variáveis, mostrando seus padrões de mudança, pode contribuir na tomada de decisão de gestores e na consolidação de conhecimentos na área. Pesquisas que aumentem a compreensão dessas variáveis permitem aprimorar a implantação de novos processos na organização, seja no nível individual, das tarefas ou dos grupos (Pasetto \& Mesadri, 2011). Portanto, o objetivo geral desta pesquisa é analisar as relações entre as autopercepções de desempenho no trabalho com clima organizacional e satisfação no trabalho de duas organizações.

\section{MÉTODO}

\section{Participantes}

Participaram da pesquisa os funcionários de duas organizações do contexto privado, sendo uma especializada em produtos médicos e a outra um clube social, fundado há mais de 40 anos, em Brasília. Sua estrutura é ampla e inclui ginásio, quadra poliesportiva, churrasqueira, piscina olímpica, piscina recreativa e campo de 
futebol. Tem atualmente 170 funcionários e conta com grande número de associados. Ao mencionar o clube social, será utilizado o termo Alfa.

A empresa do segmento de produtos médicos é uma organização de médio porte, com 60 funcionários (ver classificação sugerida pelo Instituto Brasileiro de Geografia e Estatística (IBGE)), localizada no Distrito Federal e com vendas em todo o Brasil. Foi fundada há mais de 20 anos e atua principalmente nos segmentos de cardiologia, medicina desportiva e performance humana. Será referida como Beta.

Em Alfa foi obtida a participação de $54 \%$ dos funcionários $(N=96)$ e em Beta, de $93 \%(N=56)$. Considerando a amostra de 152 trabalhadores das duas organizações, participaram mais homens do que mulheres (57\%), com ensino médio completo como nível de escolaridade predominante (28\%). A média de idade foi de 35 anos $(D P=11,242)$, a média de tempo de atividade remunerada de 13,11 anos $(D P=9,92)$ e a média de tempo na organização de 6,74 anos $(D P=7,80)$.

\section{Instrumentos}

Foram utilizadas três escalas de avaliação validadas por diferentes autores: Escala de Autoavaliação de Desempenho no Trabalho (EGDT), para medir a autoavaliação de desempenho no trabalho (Queiroga, Borges-Andrade, \& Coelho Junior, 2015); a ECO versão reduzida para medir o clima organizacional (Vieira \& Queiroga, 2013); e a EST versão reduzida para avaliar a satisfação no trabalho (Siqueira, 2008). Além de responder as três escalas, que totalizaram 74 itens, os participantes forneceram alguns dados demográficos: idade, sexo, grau de escolaridade, tempo de atividade remunerada e tempo de serviço na organização.

\section{Escala de Autoavaliação de Desempenho no Trabalho}

A escala contempla dois fatores de desempenho: o Fator I $(\alpha=0,88)$, que engloba o Desempenho contextual, avaliando a proatividade e as ações voltadas para agir de forma estratégica; e o Fator II ( $\alpha=0,82)$, envolvendo o Desempenho voltado para a tarefa, composto pelos comportamentos do indivíduo para executar suas funções. Sua versão final possui 20 itens. Mede o desempenho por meio da autoavaliação do respondente em uma escala que vai de 1 (nunca) até 5 (sempre). Resultados entre 1 e 2,9 indicam incidência insuficiente de comportamentos no trabalho, valores entre 3 e 3,9 indicam que os comportamentos ocorrem com frequência mediana e valores maiores que 4 apontam frequência suficiente de comportamentos.

\section{Escala de Clima Organizacional}

Foi usada a versão reduzida da escala (Vieira \& Queiroga, 2013), que possui 39 itens, com seis fatores. O fator Apoio da chefia possui $(\alpha=0,90) 5$ itens e envolve suporte afetivo e operacional da chefia. $O$ fator Apoio da organização $(\alpha=0,91)$ possui 9 itens e envolve suporte afetivo, estrutural e operacional fornecido aos empregados. O fator Recompensa $(\alpha=0,91)$ tem 5 itens, abordando as formas de recompensa usadas pela empresa para premiar a qualidade, a produtividade, o esforço e o desempenho do trabalhador. $\mathrm{O}$ fator Conforto físico $(\alpha=0,89)$ é medido por 9 itens, englobando a segurança, o conforto e o ambiente físico da empresa. O quinto fator é Controle/pressão $(\alpha=0,76)$, com 7 itens, envolvendo a pressão e o controle exercidos pela empresa e supervisores sobre o comportamento dos empregados. Por fim, o fator Coesão entre os colegas $(\alpha=0,84)$ possui 4 itens, e refere-se à união, aos vínculos e à colaboração entre os colegas de trabalho. Para esta pesquisa, o participante assinalou um valor para cada item, indo de 1 (discordo) até 5 (concordo). Valores maiores que 4 indicam bom clima, e menores que 2,9 mostram clima ruim. Ocorre o inverso apenas no fator Controle/ pressão, em que valores maiores de 4 indicam clima ruim, e menores que 2,9 bom clima (Martins, 2008).

\section{Escala de Satisfação no Trabalho}

Foi usada a versão reduzida da escala, validada por Siqueira (2008), a mesma autora da versão completa. A escala possui 15 itens e é dividida em cinco fatores: (a) Satisfação com os colegas $(\alpha=0,86)$ refere-se ao contentamento com a colaboração, a amizade e o relacionamento com os colegas de trabalho; (b) Satisfação com o salário $(\alpha=0,92)$, é o contentamento com o que recebe como salário se comparado com o quanto trabalha e com os esforços feitos na realização de suas atividades; (c) Satisfação com a chefia $(\alpha=0,90)$ é o contentamento com a organização e capacidade profissional do chefe e com o seu entendimento com os subordinados; (d) Satisfação com a natureza do trabalho $(\alpha=0,82)$ consiste no contentamento com o interesse despertado pelas tarefas e com a sua variedade; e (e) Satisfação com as promoções $(\alpha=0,81)$, que abrange o contentamento com o número de vezes que já recebeu promoções e com a maneira de a empresa realizar promoções. Cada um dos fatores é 
medido por meio de três itens. O participante da pesquisa irá assinalar, então, o número que indica o grau de satisfação ou insatisfação com cada enunciado, com opções variando de 1 (insatisfeito) a 5 (satisfeito). Valores maiores que 4 tendem a indicar satisfação, valores menores que 2,9 tendem a indicar insatisfação e valores entre 3 e 3,9 demonstram estado de indiferença.

Em virtude de os instrumentos utilizados já terem indicadores psicométricos que apontam para evidências de validade consideradas adequadas, foi conduzido, antes da aplicação, apenas um procedimento de validação semântica para confirmar a pertinência dos instrumentos nos campos estudados. Dessa forma, pediu-se que os participantes fizessem marcações com sugestões de alteração em itens considerados confusos, palavras de difícil compreensão ou qualquer outra modificação considerada relevante. $\mathrm{Na}$ validação semântica, nenhum dos cinco participantes apresentou sugestão de alteração. Assim, manteve-se o protocolo de pesquisa inalterado e as respostas foram consideradas na análise dos dados.

\section{Procedimentos de coleta de dados e cuidados éticos}

A coleta de dados ocorreu a partir do preenchimento das três escalas pelos funcionários das organizações. A partir do contato dos pesquisadores com a equipe de gestão, as instituições manifestaram interesse em realizar diagnóstico sobre as variáveis envolvidas na pesquisa. Diante disso, foi apresentado um projeto explicitando as condições para a coleta de dados, bem como o prazo para a sua realização. Os dados foram colhidos presencialmente de forma coletiva durante os intervalos de trabalho. Os pesquisadores acompanharam todo o processo. Todos os participantes preencheram o Termo de consentimento livre e esclarecido e a pesquisa teve projeto previamente aprovado por Comitê de Ética em Pesquisa.

\section{Procedimentos de análise de dados}

Os dados foram tabulados e analisados com o auxílio do pacote estatístico SPSS (Statistical Package for Social Sciences), versão 20.0, por meio do qual foram calculadas as análises descritivas e inferenciais (medidas de tendência central e de dispersão, correlações e regressões lineares múltiplas). Para tanto, foram calculados dois fatores de desempenho, seis fatores de clima organizacional e cinco fatores de satisfação no trabalho. Além dos fatores das escalas, as variáveis demográficas idade, tempo de atividade remunerada e tempo na organização foram consideradas.

\section{RESULTADOS}

Para avaliar possíveis multicolinearidades entre as variáveis, foram calculadas correlações de Pearson entre os fatores. Também foram consideradas três variáveis demográficas, idade, tempo de atividade remunerada e tempo na organização. A Tabela 1 apresenta os resultados. 
TABELA 1. Análise de correlações entre os fatores Desempenho, Clima organizacional e Satisfação no trabalho nas duas organizações

\begin{tabular}{|c|c|c|c|c|c|c|c|c|c|c|c|c|c|c|c|c|}
\hline & $\begin{array}{c}\text { DT } \\
(\alpha=0,78)\end{array}$ & $\begin{array}{c}\text { DC } \\
(\alpha=0,88)\end{array}$ & $\begin{array}{c}\text { CC } \\
(\alpha=0,90)\end{array}$ & $\begin{array}{c}\text { CO } \\
(\alpha=0,93)\end{array}$ & $\begin{array}{c}\text { CR } \\
(\alpha=0,94)\end{array}$ & $\begin{array}{c}\text { CF } \\
(\alpha=0,86)\end{array}$ & $\begin{array}{c}\text { CP } \\
(\alpha=0,72)\end{array}$ & $\begin{array}{c}\text { CCC } \\
(\alpha=0,83)\end{array}$ & $\begin{array}{c}\text { SCo } \\
(\alpha=0,82)\end{array}$ & $\begin{array}{c}\text { SP } \\
(\alpha=0,71)\end{array}$ & $\begin{array}{c}\text { SS } \\
(\alpha=0,88)\end{array}$ & $\begin{array}{c}\text { SN } \\
(\alpha=0,69)\end{array}$ & $\begin{array}{c}\text { SCh } \\
(\alpha=0,86)\end{array}$ & Id & TA & Tо \\
\hline DT & 1 & & & & & & & & & & & & & & & \\
\hline DC & $0,85^{\star \star}$ & 1 & & & & & & & & & & & & & & \\
\hline CC & $0,32^{* *}$ & $0,38^{\star *}$ & 1 & & & & & & & & & & & & & \\
\hline $\mathrm{CO}$ & $0,21^{*}$ & $0,27^{\star *}$ & $0,82^{* *}$ & 1 & & & & & & & & & & & & \\
\hline $\mathrm{CR}$ & $-0,08$ & $-0,05$ & $0,45^{* *}$ & $0,64^{\star *}$ & 1 & & & & & & & & & & & \\
\hline CF & $0,3^{* *}$ & $0,28^{* *}$ & $0,62^{* *}$ & $0,72^{* *}$ & $0,57^{\star *}$ & 1 & & & & & & & & & & \\
\hline $\mathrm{CP}$ & $0,35^{\star \star}$ & $0,31^{\star *}$ & 0,10 & 0,06 & $-0,01$ & 0,02 & 1 & & & & & & & & & \\
\hline CCC & $0,29^{\star \star}$ & $0,25^{\star \star}$ & $0,60^{\star *}$ & $0,55^{\star \star}$ & $0,36^{\star *}$ & $0,45^{\star *}$ & 0,00 & 1 & & & & & & & & \\
\hline SCo & $0,31^{\star *}$ & $0,24^{\star *}$ & $0,44^{\star *}$ & $0,44^{* *}$ & $0,33^{* *}$ & $0,47^{\star *}$ & 0,04 & $0,59^{* *}$ & 1 & & & & & & & \\
\hline SP & 0,07 & 0,12 & $0,41^{* *}$ & $0,46^{\star *}$ & $0,60^{\star *}$ & $0,43^{\star \star}$ & 0,02 & $0,33^{\star *}$ & $0,32^{* *}$ & 1 & & & & & & \\
\hline SS & $-0,05$ & 0,01 & $0,33^{\star *}$ & $0,38^{* *}$ & $0,51^{\star *}$ & $0,40^{\star *}$ & 0,04 & $0,19^{\star *}$ & $0,21^{*}$ & $0,65^{\star *}$ & 1 & & & & & \\
\hline SN & $0,33^{\star *}$ & $0,37^{* *}$ & $0,43^{\star \star}$ & $0,43^{\star *}$ & $0,40^{* *}$ & $0,53^{\star *}$ & 0,11 & $0,42^{\star *}$ & $0,37^{* *}$ & $0,44^{* *}$ & $0,44^{* *}$ & 1 & & & & \\
\hline SCh & $0,3^{\star *}$ & $0,35^{\star *}$ & $0,79^{\star *}$ & $0,67^{\star *}$ & $0,37^{\star *}$ & $0,65^{\star \star}$ & 0,04 & $0,56^{\star *}$ & $0,47^{\star *}$ & $0,38^{\star *}$ & $0,32^{* *}$ & $0,55^{\star \star}$ & 1 & & & \\
\hline Id & 0,06 & 0,05 & $-0,17^{*}$ & $-0,17^{*}$ & $-0,08$ & $-0,08$ & 0,03 & $-0,17^{* *}$ & $-0,05$ & 0,06 & 0,15 & 0,15 & $-0,04$ & 1 & & \\
\hline TA & 0,06 & 0,06 & $-0,15$ & $-0,15$ & $-0,09$ & 0,02 & 0,06 & $-0,23^{* *}$ & $-0,02$ & 0,08 & 0,09 & 0,13 & 0,02 & $0,81^{\star *}$ & 1 & \\
\hline TO & 0,17 & $0,17^{*}$ & $-0,06$ & $-0,09$ & $-0,02$ & 0,01 & 0,12 & $-0,11$ & $-0,02$ & $0,20^{*}$ & 0,13 & 0,15 & 0,03 & $0,65^{\star *}$ & $0,69^{\star *}$ & 1 \\
\hline
\end{tabular}

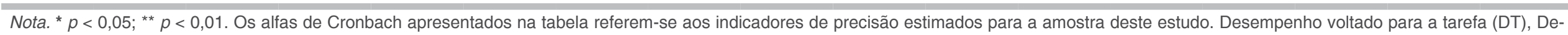

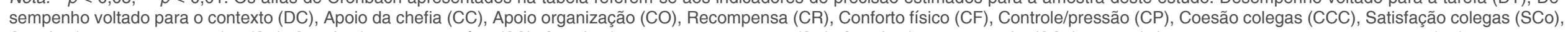

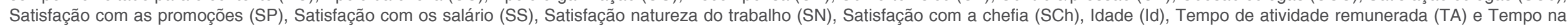
organização (TO), nas duas organizações. 
A partir da Tabela 1, observa-se que Desempenho voltado para a tarefa e Desempenho voltado para o contexto têm alta correlação entre si $(r=0,85 ; p<0,01)$, mas correlação moderada com os fatores clima e satisfação (coeficientes por volta de 0,30 para os dois construtos). Entre as variáveis do perfil, só Desempenho voltado para o contexto apresentou correlação significativa com Tempo na organização $(r=0,17 ; p<0,05)$, indicando que o tempo de casa relaciona-se mais com a apresentação de comportamentos relacionados à iniciativa e à colaboração na organização.

Apesar da similaridade entre alguns fatores de clima e satisfação, a análise de correlação permite identificar que não há sobreposição na avaliação desses construtos. A maior correlação observada foi entre os fatores Apoio da chefia e Satisfação com a chefia $(r=0,78 ; p<0,01)$. Contudo, esse não é um valor que justifica a presença de multicolinearidade (Hair, Anderson, Tatham, \& Black, 2005).

Idade e tempo de atividade remunerada apresentaram correlação elevada $(r=0,81 ; p<0,01)$, o que justifica manter apenas uma delas em análise de regressão. Embora os fatores Recompensa, Satisfação com as promoções e Satisfação com o salário não terem apresentado correlações significativas com os dois fatores de desempenho, tomou-se a decisão de mantê-los na regressão, pois, no conjunto, tais fatores podem ser úteis na explicação do modelo.

Após apresentar as correlações entre as variáveis, segue-se a apresentação das duas regressões múltiplas calculadas. Em ambas, foram inseridas como variáveis preditoras os 6 fatores de clima, os 5 fatores de satisfação, o tempo de atividade remunerada e o tempo na organização. Como variável critério, na primeira regressão foi utilizado o fator Desempenho voltado para a tarefa. Na segunda regressão, foi usado o fator Desempenho voltado para o contexto. Na Tabela 2 podem ser visualizados os resultados da primeira regressão.

TABELA 2. Análise de regressão para a variável Desempenho voltado para a tarefa (DT)

\begin{tabular}{|c|c|c|c|}
\hline Variável & $B$ & SE B & $\beta$ \\
\hline Constante & 2,63 & 0,27 & \\
\hline Apoio da chefia & 0,14 & 0,08 & 0,26 \\
\hline Apoio organização & $-0,08$ & 0,08 & $-0,14$ \\
\hline Recompensa & $-0,20$ & 0,05 & $-0,43^{*}$ \\
\hline Conforto físico & 0,22 & 0,07 & $0,36^{*}$ \\
\hline Controle/pressão & 0,17 & 0,05 & $0,25^{\star}$ \\
\hline Coesão colegas & 0,05 & 0,06 & 0,09 \\
\hline Satisfação com os colegas & 0,08 & 0,05 & 0,16 \\
\hline Satisfação com as promoções & 0,05 & 0,05 & 0,09 \\
\hline Satisfação com o salário & $-0,10$ & 0,04 & $-0,21^{*}$ \\
\hline Satisfação natureza do trabalho & 0,16 & 0,06 & $0,26^{*}$ \\
\hline Satisfação com a chefia & $-0,07$ & 0,07 & $-0,14$ \\
\hline Tempo de atividade remunerada & 0,00 & 0,01 & $-0,04$ \\
\hline Tempo na organização & 0,01 & 0,01 & 0,10 \\
\hline
\end{tabular}

Nota. $R^{2}=0,42 ; R^{2}$ ajustado $=0,35 * ; p<0,05$

As 13 variáveis preditoras de desempenho voltado para a tarefa explicaram $42 \%$ da variância do construto $\left(R^{2}=0,42 ; p<0,01\right)$. Ao se observar as contribuições individuais, as variáveis Recompensa $(\beta=-0,43 ; p<0,01)$ e Satisfação com o salário $(\beta=-0,21)$ tiveram impacto significativo e negativo, indicando que a percepção de tais variáveis impacta inversamente na maneira como os funcionários avaliam seu Desempenho voltado para a tarefa. 
Por outro lado, outras variáveis tiveram impacto positivo na variável critério. A percepção de Conforto físico $(\beta=0,36 ; p<0,05)$ e de Controle/pressão $(\beta=0,25 ; p<0,05)$ são fatores de clima organizacional que impactaram diretamente a autoavaliação de Desempenho voltado para a tarefa. Além destas, a Satisfação com a natureza do trabalho $(\beta=0,26 ; p<0,05)$ também apresentou impacto significativo na explicação dessa variável critério. A seguir, na Tabela 3 , podem ser visualizados os resultados do segundo modelo de regressão múltipla com o fator Desempenho voltado para o contexto como variável critério.

TABELA 3. Análise de regressão para a variável Desempenho voltado para o contexto (DC)

\begin{tabular}{|c|c|c|c|}
\hline Variável & $B$ & SE B & $\beta$ \\
\hline Constante & 2,53 & 0,32 & \\
\hline Apoio da chefia & 0,21 & 0,09 & $0,36^{\star}$ \\
\hline Apoio organização & $-0,01$ & 0,10 & $-0,02$ \\
\hline Recompensa & $-0,21$ & 0,60 & $-0,41^{*}$ \\
\hline Conforto físico & 0,11 & 0,09 & 0,15 \\
\hline Controle/pressão & 0,15 & 0,06 & $0,19^{\star}$ \\
\hline Coesão colegas & $-0,02$ & 0,06 & $-0,03$ \\
\hline Satisfação com os colegas & 0,05 & 0,06 & 0,08 \\
\hline Satisfação com as promoções & 0,08 & 0,07 & 0,12 \\
\hline Satisfação com o salário & $-0,09$ & 0,05 & $-0,16$ \\
\hline Satisfação natureza do trabalho & 0,23 & 0,07 & $0,32^{*}$ \\
\hline Satisfação chefia & $-0,04$ & 0,08 & $-0,07$ \\
\hline Tempo de atividade remunerada & 0,00 & 0,01 & $-0,04$ \\
\hline Tempo na organização & 0,01 & 0,01 & 0,10 \\
\hline
\end{tabular}

Nota. $R^{2}=0,38 ; R^{2}{ }_{\text {ajustado }}=0,30 * ; p<0,05$

O segundo modelo, com as mesmas 13 variáveis preditoras, conseguiu explicar aproximadamente 37\% da variável Desempenho voltado para o contexto $\left(R^{2}=0,38 ; p<0,01\right)$. A variável Recompensa também teve impacto significativo e negativo $(\beta=-0,41 ; p<0,05)$, mas, ao contrário do modelo anterior, não houve contribuição significativa da Satisfação com o salário nessa regressão.

Com relação aos fatores de clima organizacional, assim como no modelo anterior, Controle/pressão ( $\beta=$ $0,19 ; p<0,05)$ também foi significativo para explicar a autoavaliação de Desempenho voltado para o contexto, mas não houve contribuição significativa da variável Conforto físico. Em lugar dela, o Apoio da chefia, que não contribuiu no modelo anterior, foi significativo e positivo $(\beta=0,36 ; p<0,05)$.

O único fator de satisfação que apresentou contribuição significativa foi Satisfação com a natureza do trabalho $(\beta=0,32 ; p<0,05)$. Esse resultado indica que o Desempenho voltado para o contexto é muito mais associado com a percepção do ambiente, como o clima organizacional, do que por variáveis individuais, como a satisfação no trabalho.

Em síntese, observou-se que os modelos para a explicação dos fatores de autoavaliação de desempenho foram significativos, mas com contribuições individuais um pouco distintas. Os fatores da escala de clima organizacional, Recompensa e Controle/pressão foram significativos para explicar tanto o Desempenho voltado para a tarefa quanto para o contexto. Da mesma forma, o fator Satisfação com a natureza do trabalho foi significativo para explicar ambas as percepções de desempenho. Por outro lado, o fator de clima organizacional, Conforto físico, só apresentou contribuição significativa para explicar o Desempenho voltado para a tarefa, enquanto Apoio da chefia só foi significativo para explicar o Desempenho voltado para o contexto. 


\section{DISCUSSÃO}

Considerando os resultados encontrados, ficaram evidentes algumas semelhanças entre as escalas. Em ambas, existem fatores que indicam o clima organizacional ou a satisfação no trabalho em relação ao Apoio/ Satisfação com a chefia, à Recompensa/Satisfação com o salário e à Coesão/Satisfação com os colegas. Esses três fatores semelhantes de ambas as escalas apresentaram resultados congruentes entre si nas duas organizações, o que possibilita maior segurança ao se considerar esses fatores nos respectivos contextos de trabalho. Além disso, foram obtidos dados que corroboram a conclusão de que os conceitos de clima organizacional e satisfação no trabalho são diferentes, pois as correlações entre os fatores semelhantes, como Recompensa e Satisfação com o salário $(r=0,51 ; p<0,05)$, Coesão entre os colegas e Satisfação com os colegas $(r=0,59 ; p$ $<0,05)$ e Apoio da chefia e Satisfação com a chefia $(r=0,79 ; p<0,05)$ foram moderadas. Assim, apesar de semelhantes, as correlações indicam que os conceitos são diferentes, ainda que estabeleçam relações entre si, conforme observa-se na definição conceitual dos construtos (Martins, 2008; Siqueira, 2008; Tamayo \& Borges, 2001; Wrigth \& Cropanzano, 2000).

Melo (2011), em sua pesquisa, reconhece a influência de aspectos físicos, psicológicos e sociais que interferem no clima organizacional, refletindo no bem-estar das pessoas. Esse bem-estar, por sua vez, diz respeito à satisfação no trabalho, ao quanto as características da organização agradam o funcionário e o fazem se sentir bem (Martins, 2008). Ainda, os conceitos são distintos pelo fato de a satisfação medir o quanto o funcionário "gosta ou não" de aspectos do ambiente de trabalho, enquanto no clima é mensurada a percepção de presença ou ausência desses aspectos (Tamayo \& Borges, 2001). Dessa forma, as semelhanças são quanto aos aspectos abordados nos dois construtos e as diferenças são quanto ao critério de mensuração. Ainda conforme Tamayo e Borges (2001), o clima seria uma medida cognitiva, enquanto a satisfação seria de natureza afetiva. Esta pesquisa vai ao encontro dessa premissa, pois, de fato, os três fatores nas escalas apresentam correlações moderadas entre si, conforme apontado, mas não são demasiadamente elevadas.

Em relação às regressões múltiplas realizadas, obtiveram-se resultados cujos modelos são significativos. Cabe destacar a contribuição significativa e negativa para o fator Recompensa nos dois modelos, e do fator Satisfação com o salário na explicação de Desempenho voltado para a tarefa. Isto é, a percepção ruim de salário acabou impactando positivamente a avaliação de desempenho dos participantes. Ao se analisar os contextos estudados, observa-se que os participantes ocupavam cargos de baixa complexidade (em Alfa) e média complexidade (em Beta). De certa forma, é esperado que os participantes percebam que sua remuneração é modesta, mas que as tarefas estão sendo cumpridas com excelência. É importante esclarecer que esse resultado não permite sinalizar que quanto menor o salário, melhor o desempenho do trabalhador.

Seguindo a análise das regressões, observa-se que, nos dois modelos, o Controle/pressão teve impacto significativo na explicação do desempenho. Nesse sentido, cabe destacar Bendassolli e Malvezzi (2013), que afirmam existirem três grandes linhas explicativas para os determinantes do desempenho. Primeiro, a linha das diferenças individuais, em que se destacam os preditores personalidade, experiência, habilidades cognitivas, motivação e autoeficácia. Em uma segunda linha, são ressaltados aspectos do ambiente, como estilos de liderança, clareza de papéis, cultura organizacional e qualidade dos relacionamentos interpessoais. Uma terceira linha aborda processos cognitivos para realizar as atividades de trabalho, a partir da compreensão do problema, da elaboração de um plano de ação e da capacidade de manter o foco. Assim, pode-se associar o Controle/pressão com aspectos do ambiente de trabalho que, conforme Bendassolli e Malvezzi (2013), impactam o desempenho.

Além da percepção do salário, o fator Satisfação com a natureza do trabalho foi o único que obteve contribuição significativa nos dois modelos de regressão. Observa-se que pelo menos um dos componentes da satisfação no trabalho relaciona-se às autoavaliações de desempenho alinha-se à afirmação de Siqueira (2008) de que esse construto leva a um aumento do desempenho e da produtividade dos funcionários.

A pesquisa também foi importante por demonstrar a utilidade das três escalas utilizadas (EGDT, EST e ECO), pois os resultados obtidos foram consistentes. Os três fatores semelhantes nas escalas de clima e satisfação tiveram resultados congruentes e, além disso, as variáveis medidas construíram dois modelos de regressão significativos. Por se tratar de instrumentos com apresentação de evidências de validade recentes, é importante alcançar resultados coerentes como os descritos neste estudo, pois tendem a reforçar o uso de tais instrumentos no diagnóstico em contexto de trabalho. 
É importante destacar ainda que, embora os construtos aqui relacionados já tenham sido bastante estudados na literatura, o diagnóstico de tais variáveis continua sendo empregado de forma recorrente no mundo corporativo para realização de intervenções. As avaliações de clima organizacional, por exemplo, são periódicas em organizações de médio e grande porte, sejam elas públicas ou privadas (Antão, 2009; Martins et al., 2004). Da mesma forma, isso ocorre com as avaliações de desempenho (Bendassolli \& Malvezzi, 2013). Por isso, é pertinente atualizar a pesquisa no que diz respeito à avaliação dessas variáveis e estimular que o seu diagnóstico em contextos de trabalho possa ser mais completo quando os construtos relacionam-se em um modelo explicativo em vez de manter avaliações isoladas de cada variável.

\section{REFERÊNCIAS}

Antão, C. S. (2009). Pesquisa de clima com base na implantação de políticas de desempenho organizacional (Monografia de especialização não publicada). Universidade Católica de Goiás, Goiás.

Barbosa, M. C. F. G. C. (2011). Relações entre estilos gerenciais e clima organizacional: Um estudo em empresas juniores do Distrito Federal (Monografia de graduação). Recuperado de http://bdm.unb.br/handle/10483/1676

Bendassolli, P. F., \& Malvezzi, S. (2013). Desempenho no trabalho: Modelos teóricos e desafios à gestão. In L. O. Borges \& L. Mourão (Orgs.), O trabalho e a organização: Atuações a partir da psicologia (pp.53-84). Porto Alegre: Artmed.

Dutra, J. S. (2004). Competências: Conceitos e instrumentos para gestão de pessoas na empresa moderna. São Paulo: Atlas.

Fonseca, C. A. M., \& Bastos, A. V. B. (2003). Criatividade e comprometimento organizacional: Suas relações com a percepção de desempenho no trabalho. Revista Psicologia Organizações e Trabalho, 3(1), 61-88.

Garrido, T. C. J. (2009). Satisfação no trabalho: Um estudo no Superior Tribunal de Justiça (Monografia de especialização). Recuperado de http://bdm.unb.br/handle/10483/1542

Glisson, C. (2007). Assessing and changing organizational culture and climate for effective services. Research on Social Work Pratice, 17(6), 736-747. doi: 10.1177/10497315073 01659

Hair, J. F., Anderson, R. E., Tatham, R. L., \& Black, W. C. (2005). Análise multivariada de dados. Porto Alegre: Bookman.

Magno, D., \& Bezerra, S. (2012). Percepção do clima organizacional no setor de vendas da Ability Comunicação Integrada LTDA no agreste e sertão de Pernambuco (Monografia de graduação não publicada). Faculdade Vale do Ipojuca, Caruaru.

Martins, M. C. F. (2008). Clima organizacional. In M. M. M. Siqueira (Org.), Medidas do comportamento organizacional: Ferramentas de diagnóstico e gestão (pp. 29-40). Porto Alegre: Artmed.

Martins, M. C. F., Oliveira, B., Silva, C. F., Pereira, K. C., \& Sousa, M. R. (2004). Construção e validação de uma escala de clima organizacional. Revista Psicologia: Organizações e Trabalho, 4(1), 37-60.

Maximiano, A. C. (2007). Introdução à administração. São Paulo: Atlas.

Melo, R. A. (2011). A satisfação dos colaboradores de uma rede de supermercados de Rio Branco em relação aos indicadores de qualidade de vida no trabalho (Monografia de graduação). Recuperado de http://bdm.unb.br/handle/10483/3256

Pasetto, N. V., \& Mesadri, F. E. (2011). Comportamento organizacional: Integrando conceitos da administração e da psicologia. Curitiba: Ibpex

Pedro, R. F. (2006). Qualidade de vida no trabalho (Monografia de especialização). Recuperado de http://www.avm.edu.br/ monopdf/9/RICARDO\%20FERNANDES\%20PEDRO.pdf

Peixoto, A., \& Caetano, A. (2013). Avaliação de desempenho. In L. O. Borges \& L. Mourão (Orgs.), O trabalho e a organização: Atuações a partir da psicologia (pp.528-554). Porto Alegre: Artmed.

Porter, M. E. (1996). Estratégia competitiva: Técnicas para análise de indústrias e da concorrência. Rio de Janeiro: Campus.

Puente-Palacios, K., \& Martins, M. C. F. (2013). Gestão do clima organizacional. In L. O. Borges \& L. Mourão (Orgs.), O trabalho e a organização: Atuações a partir da psicologia (pp.253-278). Porto Alegre: Artmed.

Queiroga, F., Borges-Andrade, J. E., \& Coelho Junior, F. A. (2015). Desempenho no trabalho: Uma proposta de avaliação geral por meio de autopercepções. In K. Puente-Palacios \& A. Peixoto, Ferramentas de diagnóstico para organizações e trabalho - Um olhar a partir da psicologia (pp. 36-45). Porto Alegre: Artmed.

Schröder, L. P. (2012). A satisfação do servidor público no trabalho e o reflexo desse resultado na organização (Monografia de especialização). Recuperado de http://bibliodigital.unijui.edu.br:8080/xmlui/handle/123456789/802

Silva, N. (2015). Cultura e clima organizacional. In P.F. Bendassolli \& J. E. Borges-Andrade (Orgs.), Dicionário de psicologia do trabalho e das organizações (pp. 261-271). São Paulo: Casa do Psicólogo. 
Siqueira, M. M. M. (2008). Satisfação no trabalho. In M. M. M. Siqueira (Org.), Medidas do comportamento organizacional: Ferramentas de diagnóstico e gestão (pp. 265-274). Porto Alegre: Artmed.

Sonnentag, S., \& Frese, M. (2002). Performance concepts and performance theory. In S. Sonnentag (Org.), Psychological management of individual performance (pp. 3-25). Chichester: Jonh Wiley \& Sons.

Sousa, J. S., \& Garcia, F. C. (2011). Clima organizacional: Um estudo de caso em uma rede de farmácias no interior de Minas Gerais. Gestão \& Regionalidade, 27(79), 22-31. doi: 10.13037/gr.vol27n79.917

Tamayo, A., \& Borges, L. O. (2001). Valores del trabajo y valores de las organizaciones. In M. Ros \& V. Gouveia (Orgs.), Psicología social de los valores humanos: Desarrollos teóricos (pp. 325-352). Madrid: Biblioteca Nueva.

Vieira, S. R. F., \& Queiroga, F. (2013). Validação e aplicação da Escala de Clima Organizacional - ECO reduzida. Anais do VIII Congresso Norte-Nordeste de Psicologia. Fortaleza: Centro de Eventos do Ceará.

Wrigth, T. A., \& Cropanzano, R. (2000). Psychological well-being and job satisfaction as predictors of job performance. Journal of Occupational Health Psychology, 5(1), 84-94. doi: 10.1037//1076-8998.5.1.84 